\title{
Moderate-Grade Germinal Matrix Haemorrhage Activates Cell Division in the Neonatal Mouse Subventricular Zone
}

\author{
William J. Dawes ${ }^{a}$ Xinyu Zhang ${ }^{a}$ Stephen P.J. Fancy ${ }^{b, c}$ David Rowitch ${ }^{b, c}$ \\ Silvia Marino ${ }^{a}$ \\ a Blizard Institute, Barts and The London School of Medicine and Dentistry, Queen Mary University of London, \\ London, UK; Departments of ${ }^{b}$ Pediatrics and c Neurosurgery, Eli and Edythe Broad Institute for Stem Cell Research \\ and Regeneration Medicine and Howard Hughes Medical Institute, University of California San Francisco, \\ San Francisco, CA, USA
}

\section{Keywords}

Neural stem/progenitor cells · Postnatal gliogenesis . Postnatal neurogenesis . Germinal matrix haemorrhage . Mouse models

\begin{abstract}
Precise temporal and spatial control of the neural stem/progenitor cells within the subventricular zone (SVZ) germinal matrix of the brain is important for normal development in the third trimester and the early postnatal period. The high metabolic demands of proliferating germinal matrix precursors, coupled with the flimsy structure of the germinal matrix cerebral vasculature, are thought to account for the high rates of haemorrhage in extremely- and very-lowbirth-weight preterm infants. Germinal matrix haemorrhage can commonly extend to intraventricular haemorrhage (IVH). Because neural stem/progenitor cells are sensitive to microenvironmental cues from the ventricular, intermediate, and basal domains within the germinal matrix, haemorrhage has been postulated to impact neurological outcomes through aberration of normal neural stem/ progenitor cell behaviour. We developed an animal model
\end{abstract}

\section{KARGER}

E-Mail karger@karger.com www.karger.com/dne of neonatal germinal matrix haemorrhage using stereotactic injection of autologous blood into the mouse neonatal germinal matrix. Pathological analysis at 4 days postinjury showed high rates of intraventricular extension and ventricular dilatation but low rates of parenchymal disruption outside the germinal zone, recapitulating key features of human "Papile grade III" IVH. At 4 days postinjury we observed proliferation in the wall of the lateral ventricle with significantly increased numbers of transient amplifying cells within the SVZ and the corpus callosum. Analysis at 21 days postinjury revealed that cortical development was also affected, with increased neuronal and concomitant reduced oligodendroglial differentiation. At the molecular level, we showed downregulation of the expression of the transmembrane receptor Notch2 in $C D 133^{\text {tve }}$ cells of the SVZ, raising the possibility that the burst of precocious proliferation seen in our experimental mouse model and the skewed differentiation could be mediated by downregulation of the Notch pathway within the proximal/ventricular domain. These findings raise the possibility that Notch regulation plays a critical role in mediating the response of the neonatal SVZ to ischaemic and haemorrhagic insults.

(c) 2017 S. Karger AG, Basel

William J. Dawes or Silvia Marino

Blizard Institute

4 Newark Street

London E1 2AT (UK)

E-Mailw.dawes@qmul.ac.uk or s.marino@qmul.ac.uk 


\section{Introduction}

Delayed primigravida (first pregnancy) and the use of in vitro fertilisation have contributed to an increase in the incidence of premature birth in all developed countries $[1,2]$ and, despite advances in perinatal care, haemorrhage within the germinal matrix (GM) remains a commonly recognised complication seen in up to $45 \%$ of extremely premature babies weighing 500-750 g [3]. The cause of brain injury associated with premature birth is complex and multifactorial, with ischaemia [4] and inflammation [5] playing key roles. In addition, outcome has been shown to correlate with the severity of haemorrhage, with extension into the ventricle and loss of brain parenchyma secondary to porencephalic cyst formation being associated with significant neurodevelopmental disabilities [6-8]. Preventing premature birth and reducing the incidence of haemorrhage remain key research goals. However, the need for new modalities of treatment to limit neurodisability in this vulnerable patient group is clearly evident.

In order for normal brain development to take place, the behaviour of neural stem/progenitor cells (NSPC) is tightly regulated in both a temporal and a spatial fashion. This occurs through the balance of cell-intrinsic mechanisms and microenvironmental factors $[9,10]$. The microenvironment within the GM in which the neural stem cells (NSC) reside can be conceptualised as consisting of 3 domains [10]: the proximal/ventricular domain which responds to signalling within the CSF [11] and from interaction with the ependymal cells [12], the intermediate zone in which the NSC responds to cues arising from the intermediate progenitor cells $[13,14]$ and neurotransmitters released within the subventricular zone (SVZ) [15], and the distal/basal domain which is under the influence of cues from the circulation and endothelial cells [16]. Plausible mechanisms can be envisaged through which any and all of these microenvironmental domains could be affected due to germinal matrix haemorrhage (GMH).

Whilst GABAergic interneurons are known to arise from the SVZ in the final trimester [17-19], lineage-tracing experiments have highlighted the critical role that the GM plays in the production of astrocytic and oligodendrocytic precursors [20], with the majority of oligodendrocytes developing during late embryogenesis and early postnatal life [21]. This surge in progenitor formation coincides with the peak incidence of GMH (23-28 weeks) and, given the critical role that the oligodendrocyte lineage is likely to play in the aetiology of encephalopathy of

Neural Stem Cells and Neonatal Brain Haemorrhage prematurity [22], we hypothesised that GMH might be responsible for a primary stem cell disorder in an otherwise developmentally normal brain (i.e., no underlying genetic/pathological abnormality), making it an appealing target for therapeutic intervention.

GMH is recognised to have both destructive and developmental impacts on the developing brain of the premature neonate [23]. To date, published models of intraventricular haemorrhage (IVH) have focused on modelling severe haemorrhage, with large parenchymal defects seen [24-27]. This approach is likely to mask the more subtle developmental impact of IVH on the NSPC within the SVZ; as such, we endeavoured to produce a model with minimal cortical disruption to uncover this subtle mechanism.

Combining stereotactic injection of autologous blood at P0 [28] with a thymidine labelling strategy at P1 [29], we showed that GMH caused activation of proliferation in the wall of the lateral ventricle, which eventually resulted in an altered cellular composition of the cortex with an increased number of neuronal elements and a concomitant depletion of oligodendrocytes. Expression analysis of the CD133/prominin-positive cell fraction (a transmembrane glycoprotein expressed by NSC and ependymal cells within the lateral ventricle during early postnatal development) [30] demonstrated downregulation in the expression of Notch2, a well-known regulator of NSPC function in the proximal/ventricular domain [9, 31], in these cells following GMH.

\section{Materials and Methods}

Animals

All procedures had Home Office approval (Animals Scientific Procedures Act 1986, PPL 70/7275). C57BL/6 mice were used throughout. Cages were checked daily and intracranial autologous blood injections were undertaken on the afternoon of the first day of life.

Stereotactic Intracranial Injection of Autologous Blood

To facilitate accurate and reproducible restraint of the P0 pup, modifications were made to a Narishige stereotactic frame based on the work of Merkle et al. [28] (Fig. 1a, b). P0 pups were anaesthetised on ice for $3 \mathrm{~min}$ and $30 \mathrm{~s}$ prior to being fixed into the frame. Autologous blood collected from the tail tip (Microvette ${ }^{\mathrm{TM}}$ CB300 VWR) was injected via a customized 1-cm 30-gauge needle $1 \mathrm{~mm}$ posterior and $1.5 \mathrm{~mm}$ superior to the posterior border of the left eye with a forward angulation of 24 degrees and a depth of 2 $\mathrm{mm}$ (online suppl. Fig. S1; for all online suppl. material, see www. karger.com/doi/10.1159/000455839). In the sham group, all experimental conditions were equivalent with the exception that the mice underwent needle injection only without blood injection.
Dev Neurosci 2016;38:430-444

DOI: $10.1159 / 000455839$ 


\section{EdU Administration}

Intraperitoneal injections of EdU (12.5 mg/kg; Life Technologies $^{\mathrm{TM}}$ ) were given on day 1 of life, according to published protocols [29].

\section{Immunohistochemistry and Histology}

Mice were transcardially perfused under terminal anaesthesia with $0.9 \%$ saline followed by $4 \%$ paraformaldehyde. Brains were dissected and postfixed for $2 \mathrm{~h}$ in $4 \%$ paraformaldehyde at $4{ }^{\circ} \mathrm{C}$. Tissue was cryoprotected with $30 \%$ sucrose overnight, mounted in O.C.T. (VWR ${ }^{\mathrm{TM}}$ ) medium, and sectioned at $10 \mu \mathrm{m}$ on a cryostat $\left(\right.$ Leica $\left.^{\mathrm{TM}}\right)$.

For EdU staining, samples were blocked with 3\% BSA (Sig$\left.\mathrm{ma}^{\mathrm{TM}}\right) /$ phosphate-buffered saline $/ 0.1 \%$ Triton X100 and incubated for $30 \mathrm{~min}$ with proprietary Click-iT ${ }^{\circledR}$ solutions (Life Technologies $\left.^{\mathrm{TM}}\right)$. For immunofluorescent double staining, the following antibodies were used: rabbit anti-GFAP, 1:400 (Dako $\left.{ }^{\mathrm{TM}}\right)$; rabbit anti-NG2, 1:200 (Millipore ${ }^{\mathrm{TM}}$ ); guinea pig anti-Dcx, 1:2,000 (Merck Millipore $^{\mathrm{TM}}$ ); mouse anti-NeuN, 1:100 (Millipore ${ }^{\mathrm{TM}}$ ); mouse anti-MASH1, 1:200 (BD Biosciences ${ }^{\mathrm{TM}}$ ); rabbit anti-Iba1, 1:100 $\left(\mathrm{Wako}^{\mathrm{TM}}\right)$; and mouse anti-Olig2, 1:500 (Charles-Stiles Lab). All incubations with primary antibody were undertaken overnight. After washing with phosphate-buffered saline, sections were incubated with appropriate Alexa Fluor ${ }^{\circledR}$ secondary antibodies diluted at 1:500 (Invitrogen ${ }^{\mathrm{TM}}$ ) for $2 \mathrm{~h}$ at room temperature, washed in phosphate-buffered saline, and mounted in Fluoromount $^{\mathrm{TM}}$ (Sigma Aldrich ${ }^{\mathrm{TM}}$ ) or Vectashield ${ }^{\circledR}$ with DAPI (Vector Laboratories ${ }^{\mathrm{TM}}$ ).

\section{Volumetric Analysis Using a Cavalieri Probe}

To quantify ventricular volume, we adopted a stereological approach using the Cavalieri estimator probe within Stereoinvestigator (MBF Bioscience $\left.{ }^{\mathrm{TM}}\right)$. On the coronal plane, volumetric analysis was undertaken between the induseum griseum (anterior zero section) and the appearance of the hippocampus in continuity across the midline (posterior zero section) (online suppl. Fig. S2), with every tenth section analysed. On the sagittal plane, volume acquisition was undertaken from the sagittal zero section (online suppl. Fig. S3) (defined as the first appearance of the striatum within the rostral migratory stream) and 2 further sections at 150 and $300 \mu \mathrm{m}$ medial to the sagittal zero.

\section{Image Acquisition and Analysis}

All images were acquired using a Zeiss ${ }^{\mathrm{TM}}$ 710LSM confocal microscope and a $\times 40$ oil immersion objective lens and analysed using either tile scanning and Image ${ }^{\mathrm{TM}}$ or the Optical Fractionator probe of Stereoinvestigator (MBF Bioscience ${ }^{\mathrm{TM}}$ ). For analysis of the SVZ, 3 coronal specimens per sample were analysed [zero slide (Z), $Z+150 \mu \mathrm{m}$, and $Z+300 \mu \mathrm{m}$ ], with all cells counted within the lateral and superior wall of the ventricle within the immediate hypercellular periventricular region. Any staining which was not clearly nuclear was not counted. Within the corpus callosum, a 300-pixel-wide counting frame was taken through the corpus callosum positioned anterior to a perpendicular line taken from the anterior border of the hippocampus through the cortex (Fig. 3). Three samples per specimen were analysed (sagittal $-\mathrm{Z}, \mathrm{Z}-150$ $\mu \mathrm{m}$, and $Z-300 \mu \mathrm{m})$. Within the neocortex, quantification was undertaken on 3 sagittally orientated samples with all of the neocortex included anterior to a perpendicular line taken from the anterior border of the hippocampus (Fig. 5a).

\section{Behavioural Analysis}

Daily behavioural analysis between P2 and P21 was undertaken. Reflex development was assessed using grip strength, negative geotaxis, cliff aversion, and surface righting (online suppl. Fig. S4). Neuromotor development was assessed for $3 \mathrm{~min}$ in a Perspex open-field chamber $(50 \times 50 \mathrm{~cm})$; the number of head, shoulder pelvis lifts, head pointing and sniffing, sitting, rearing, and falls were recorded using key presses, whilst the distance travelled and the speed were recorded using proprietary Anymaze software.

Extraction Amplification and Analysis of RNA from the CD133+ve Cell Fraction

Following removal of the cerebellum and olfactory bulbs, the left hemisphere was mechanically and enzymatically homogenised using a Miltenyi Biotec ${ }^{\mathrm{TM}}$ Neural Tissue Dissociation Kit ${ }^{\circledR}$. Due to the small sample size, wash volumes were reduced and all collections were made into 1-mL Eppendorf tubes. Homogenised samples were filtered through $30-\mu \mathrm{m}$ preseparation filters (Miltenyi Biotec $^{\mathrm{TM}}$ ), incubated with CD133 microbeads (Miltenyi Biotec ${ }^{\mathrm{TM}}$ ), and passed through MACS separation columns (Miltenyi Biotec $\left.^{\mathrm{TM}}\right)$.

RNA extraction was undertaken using an RNeasy Micro Kit (Qiagen ${ }^{\mathrm{TM}}$ ). Twenty nanograms of extracted RNA from each sample was amplified using a QuantiTect Whole Transcriptome Kit (Qiagen ${ }^{\mathrm{TM}}$ ). The PCR array was then carried out on each amplified RNA product using a Mouse Stem Cell $\mathrm{RT}^{2} \operatorname{Profiler}^{\mathrm{TM}}$ (Qiagen ${ }^{\mathrm{TM}}$ ) to identify the potential targeted genes related to stem cell biology.

\section{ISH Analysis}

The Hes 5 probe was kindly donated by the Kriegstein lab (previously published in the study of Muzio et al. 2005 [32]) and the in situ hybridization was carried out according to standard protocols [33].

\section{Statistical Analysis}

Statistical analysis was undertaken using GraphPad Prism, and a $t$ test and one-way ANOVA in conjunction with Tukey's test for multiple comparisons were applied for comparisons between $2 \mathrm{da}$ tasets or multiple datasets, respectively. A linear growth model was used to compare behavioural parameters.

\section{Results}

\section{Establishment of a Mouse Model of GMH by}

Stereotactic Injection of Autologous Blood into the

\section{Neonatal Mouse SVZ}

In our experience, use of a published freehand injection of $15 \mathrm{uL}$ of autologous blood with a 26-gauge needle into the newborn mouse pup [26] caused significant morbidity and mortality and was associated with high levels of subdural extension of blood, significant damage to the surrounding cortex, and marked variability in the injection site.

Stereotactic injection in newborn mouse pups using conventional equipment is limited due to the lack of re- 
straints, as such modifications were made to a Narishige stereotactic frame based on the work of Merkle et al. [28] (Fig. 1a). The custom-made clay mould (inset in Fig. 1a), in combination with nose and body taping (Fig. 1b), facilitated accurate and reproducible restraint.

Tissue dye injection into euthanized newborn (P0) mouse pups followed by histopathological examination of coronal brain samples was used to define the injection coordinates and trajectory (online suppl. Fig. S1). The site of the blood bolus, its vicinity to the anterior SVZ, the degree of damage to the surrounding parenchyma, and the rate of intraventricular spread in comparison to subdural extension were analysed. The optimal injection coordinates were found to be: $1 \mathrm{~mm}$ posterior and $1.5 \mathrm{~mm}$ superior to the posterior border of the eye with a forward angulation of 24 degrees, at a depth of $2 \mathrm{~mm}$ (Fig. 1c; online suppl. Fig. S1). The longer trajectory used in the forward angulated approach was found to reduce bleed back along the needle tract, with an increased volume of the SVZ seen to be affected by the blood bolus; it also facilitated injection of the anterior SVZ without the risk of damaging the eye. The needle used for injection was a custom-made Hamilton ${ }^{\mathrm{TM}} 30$-gauge 1 -cm needle; lowergauge needles were associated with increased mortality and caused unacceptably high levels of tissue damage, and higher-gauge needles were liable to bending or slippage, reducing the reproducibility of the injection site. We injected $5 \mathrm{uL}$ of whole blood, an amount that is easily and atraumatically extracted from the tail tip and does not significantly impact the circulating volume; it also limits the adverse impact of bolus size on tissue distortion and intracranial pressure.

Histological analysis was carried out on coronally sectioned brains on day 1 (P1) following stereotactic blood injection on the day of birth (P0), and it showed the haematoma to be consistently located within the SVZ with variable intraventricular spreading (Fig. 1d). Minimal damage to the surrounding cortex was noted and the overall mortality was low on day 4 , with no late mortality seen. On day 4 (P4) an incipient haematoma cavity was noted within the SVZ with frequent cells of macrophagic lineage scavenging blood products within the SVZ, in keeping with siderophages (macrophages laden with iron) (Fig. 1e).

We showed that modification of the Narishige stereotactic frame as described above facilitates accurate and reproducible lesioning within the SVZ of the newborn mouse pup and could represent a useful tool to study the effect of GMH on the SVZ NSPC and on early cortical development.

Neural Stem Cells and Neonatal Brain Haemorrhage
GMH Causes Ventriculomegaly on P4, which Persists up to $P 21$

Histological examination of Nissl-stained samples demonstrated significant ventriculomegaly in the bloodinjected samples in comparison with the control samples. To quantify ventricular volume, we adopted a stereological approach using the Cavalieri estimator probe within Stereoinvestigator (MBF Bioscience ${ }^{\mathrm{TM}}$ ). Due to potential distortion of the parenchyma on the rostrocaudal plane secondary to GMH, volumetric analysis was undertaken between fixed anterior and posterior points to ensure reproducibility. Using the indusium griseum/ first appearance of the corpus callosum in continuity as the most anterior slide and the appearance of the hippocampus in continuity across the midline as the posterior slide (online suppl. Fig. S2A-D), an equal number of sections was generated for analysis [control $(n=8), 73.63 \pm$ 3.8 sections; sham $(n=5), 73.4 \pm 2.4$ sections; and GMH $(n=7), 77 \pm 4.8$ sections; $p=0.78$, ANOVA] (online suppl. Fig. S2F).

Quantitative assessment of volume on the coronal plane between the induseum griseum and the first appearance of the hippocampus in continuity revealed that blood injection caused significant ventriculomegaly at $\mathrm{P} 4$ [control $(n=7), 0.054 \pm 0.007 \mathrm{~mm}^{3}$; sham $(n=4), 0.053$ $\pm 0.003 \mathrm{~mm}^{3}$; and GMH $(n=5), 0.078 \pm 0.005 \mathrm{~mm}^{3} ; p=$ 0.02 , ANOVA] (Fig. 1f) and this was shown to persist up to P21 [control $(n=5), 0.003 \pm 0.0004 \mathrm{~mm}^{3}$, and GMH $(n=4), 0.015 \pm 0.005 \mathrm{~mm}^{3} ; p=0.03, t$ test) (Fig. $1 \mathrm{~g}, \mathrm{~h}$ ). Ventriculomegaly was not seen in the sham mice. Volume analysis within the corpus callosum, the SVZ, and the cortex at P4 and P21 demonstrated no significant difference between the control and GMH pups, indicating that the increase in ventricular volume was not due to parenchymal loss.

We have shown that the experimental model of moderate GMH we developed causes ventriculomegaly at P4 which persists up to P21, faithfully recapitulating a key feature of the human condition.

\section{GMH Causes Increased Proliferation in the Wall of} the Lateral Ventricle

To assess the impact of GMH on the NSPC within the SVZ, we adopted a thymidine labelling strategy previously published by Inta et al. [29]. The number of EdU ${ }^{+v e}$ cells within the lateral wall of the lateral ventricle was quantified after 3 days and a significant increase was found in the GMH samples as compared to controls [control $(n=$ 4), $57.5 \pm 8.605$; sham $(n=5), 80.23 \pm 5.008$; and GMH $(n=4), 165 \pm 24.09 ; p=0.0008$, ANOVA] (Fig. 2a, b).

Dev Neurosci 2016;38:430-444

DOI: $10.1159 / 000455839$ 
a

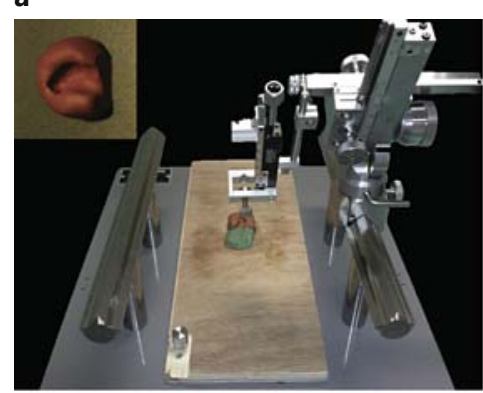

b

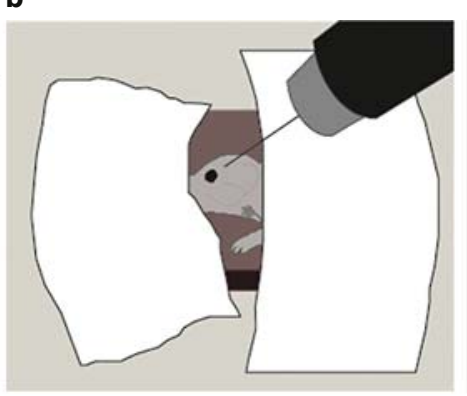

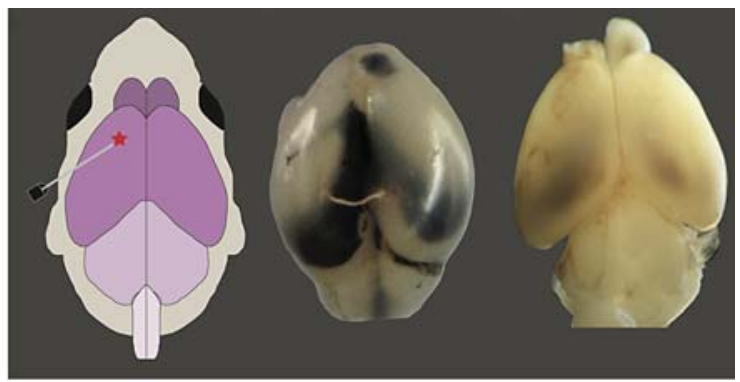

d

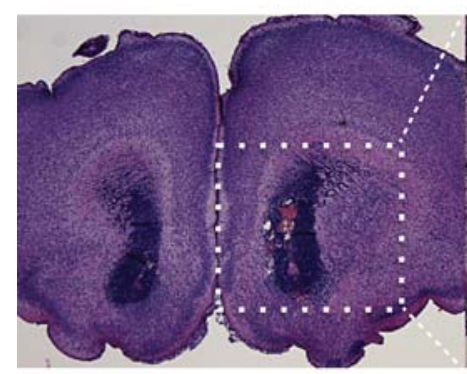

e f

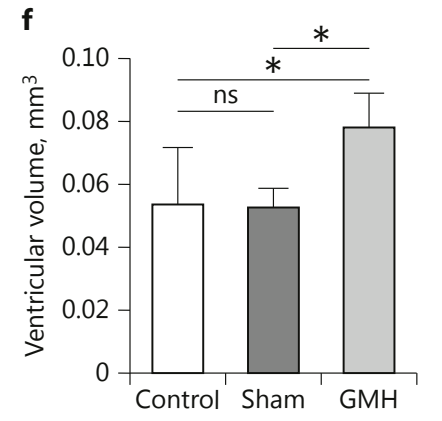

g

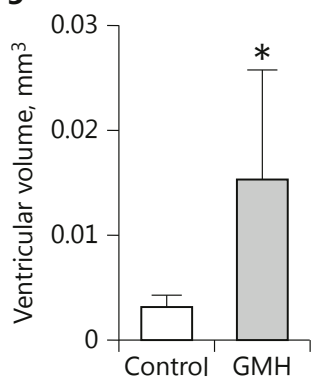

h

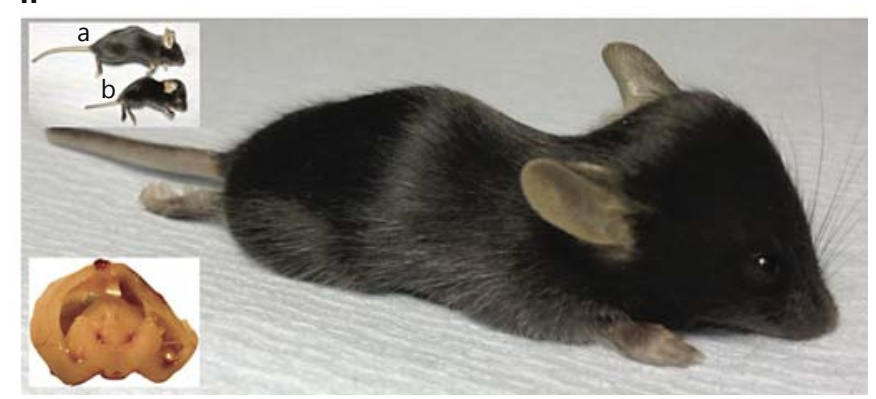

Fig. 1. Stereotactic injection of autologous blood recapitulates moderate-grade germinal matrix haemorrhage (GMH). a The Narishige stereotactic frame was modified with a clay mould (inset) secured to a custom-made board shaped to fit the space in which the proprietary metal plate would ordinarily sit. The board was secured using the housing screws shown and in combination with the taping shown in $\mathbf{b}$ this method facilitates reproducible immobilisation of the P0 mouse pup. c Schematic showing the point of bolus injection within the anterior margin of the subventricular zone (left); macroscopic picture showing the result of tissue dye injection into the subventricular zone - a small entry wound and needle tract can be seen leading to the injection bolus within the anterior subventricular zone, and bilateral intraventricular spread can also be clearly seen (middle); matching macroscopic picture showing the result of blood injection into the subventricular zone - a tiny entry wound with a very similar distribution of intraventricular blood can be seen, the relative lack of surrounding tissue damage and the absence of any subdural blood is also noted (right). d Coronal section of a P1 mouse brain stained with haematoxylin and eosin at a $\times 5$ magnification (left) and a $\times 10$ magnification (right), following stereotactic blood injection on the day of birth (P0), demonstrating haematoma within the subventricular zone (white arrow) in association with intraventricular blood (red arrow). Minimal damage to the surrounding cortex is noted. e Coronal section of a P4 mouse brain stained with haematoxylin and eosin at a $\times 10$ magnification (left) and a $\times 40$ magnification (right), demonstrating a haematoma cavity within the subventricular zone (black arrow) associated with the presence of siderophages (green arrows). $f \mathrm{GMH}$ causes ventriculomegaly at $\mathrm{P} 4$ (control, $n=7$; sham, $n=4$; and GMH, $n=5$; $p<0.05$, ANOVA). g Similarly at P21 we see persistence of ventriculomegaly (control, $n=5$, and GMH, $n=4 ; p<0.05, t$ test). $\mathbf{h}$ The persistence of hydrocephalus following GMH can be seen at P21 in the small stature and marked doming of the cranium [inset (top): comparison of a control pup (a) with a GMH pup (b) demonstrates small stature on P21 in the GMH pups; inset (bottom): coronal view of the brain with dilated lateral ventricles] $\left({ }^{*} \mathrm{p}<0.05\right)$. 


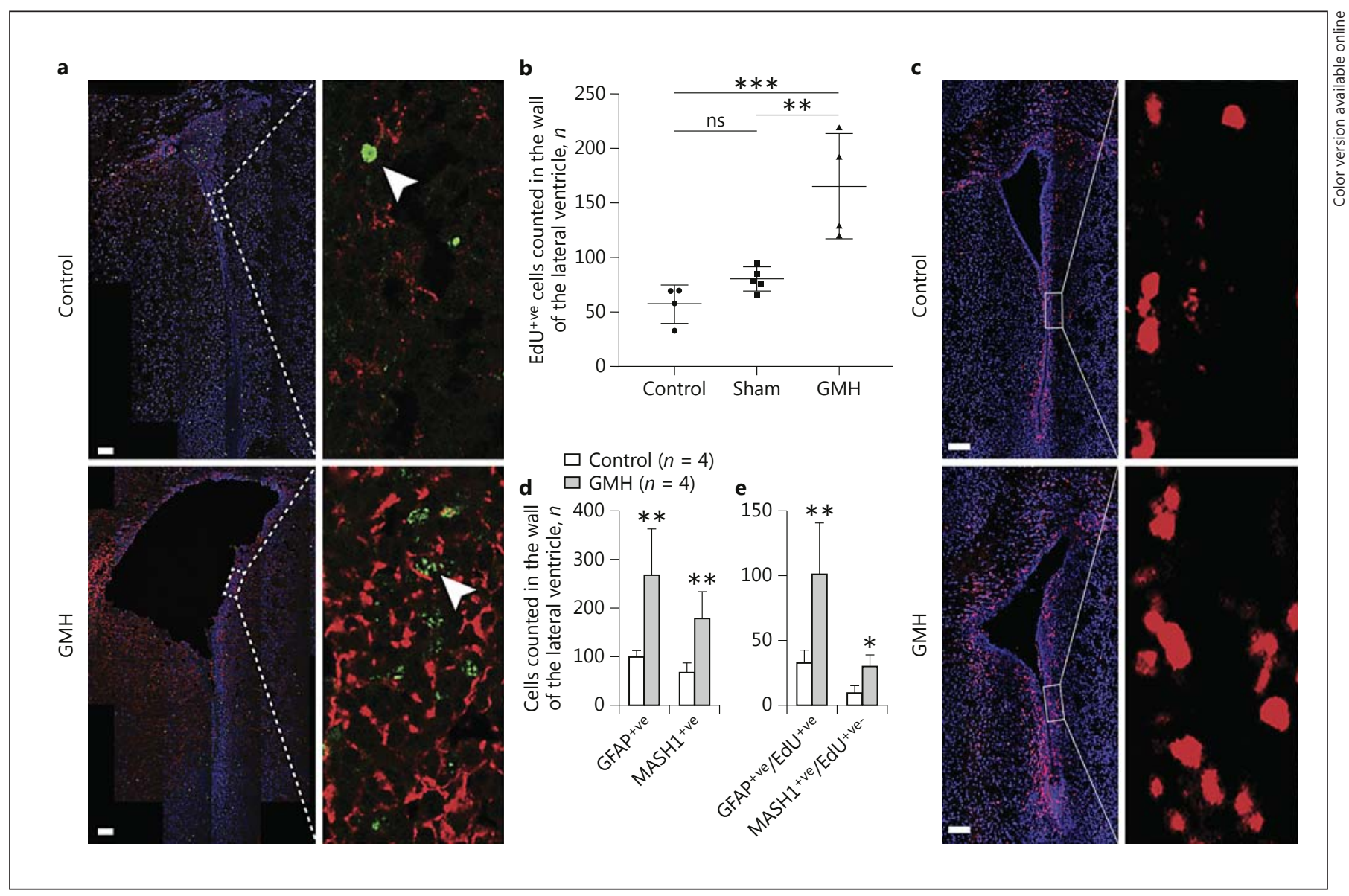

Fig. 2. Germinal matrix haemorrhage (GMH) activates proliferation in the wall of the lateral ventricle and increases the expression of GFAP and the number of MASH $1^{\text {+ve }}$ cells. a Oil confocal acquired tile scan images $(\times 40)$ of the left lateral ventricle of the P4 mouse pup, comparing control (top left and right) vs. blood-injected/GMH (bottom left and right) samples (blue, DAPI; red, GFAP; and green, EdU). In the control we see occasional EdU ${ }^{+v e}$ cells in the subventricular zone (SVZ) with minimal GFAP positivity, and in the GMH sample we see a marked increase in the number of $\mathrm{EdU}^{+\mathrm{ve}}$ cells (arrowhead) with a marked increase in GFAP immunoreactivity. Marked ventriculomegaly is also seen in the GMH sample. b Quantification of the number of EdU ${ }^{+v e}$ cells within the lateral and dorsal wall of the left lateral ventricle on $\mathrm{P} 4$ shows that GMH causes a significant increase in the number of cells counted

Importantly, sham injection did not elicit a similar effect, therefore excluding the possibility that the observed phenotype was due to the injection alone. EdU staining was found to be tightly confined to DAPI ${ }^{+v e}$ nuclei, and no picnotic/apoptotic cells were seen in the wall of the lateral ventricle. The pattern of EdU staining was also seen to change from a solid high-intensity signal in the control setting to a more fragmented and less intense signal in the

Neural Stem Cells and Neonatal Brain Haemorrhage in comparison to both the control and sham needle-only conditions (control, $n=4$; sham, $n=5$; and GMH, $n=4 ; p<0.001$, ANNOVA). c Following GMH (bottom left and right) we see a significant increase in the number of $\mathrm{MASH}^{+\mathrm{ve}}$ cells in the superior, medial, and lateral walls of the lateral ventricle in comparison to the control (top left and right) (blue, DAPI, and red, MASH1). d Increase in the number of MASH $1^{+\mathrm{ve}}$ and $\mathrm{GFAP}^{+\mathrm{ve}}$ cells in the lateral wall of the left lateral ventricle following GMH compared to the control (control, $n=4$, and GMH, $n=4$; $p<0.01$ for MASH1 and $p<0.05$ for GFAP, $t$ test). e Significant increase in GFAP ${ }^{+v e}$ / $\mathrm{EdU}^{+\mathrm{ve}}$ and $\mathrm{MASH} 1^{+\mathrm{ve}} / \mathrm{EdU}^{+\mathrm{ve}}$ cells following GMH (control, $n=$ 4, and GMH, $n=4$; $p<0.05$ for MASH1 and $p<0.05$ for GFAP. Scale bars, $100 \mu \mathrm{m}\left({ }^{*} \mathrm{p}<0.05\right.$; $^{* *} \mathrm{p}<0.01$; $\left.^{* * *} \mathrm{p}<0.001\right)$.

GMH sample, implicating a dilution of the EdU signal secondary to increased proliferation (Fig. 2a).

To determine if the increase in $\mathrm{EdU}^{+\mathrm{ve}}$ cells could be accounted for by an increase in the number of transient amplifying cells, we costained for the nuclear marker MASH1 (ASCL1) which has been shown to be expressed at high levels in transient amplifying cells [9]. This demonstrated a significant increase in the number of 
MASH $1^{+v e}$ cells within the wall of the lateral ventricle in the GMH samples [control $(n=4), 67 \pm 10.24$, and GMH $(n=4), 178 \pm 27.84 ; p=0.0096, t$ test] (Fig. $2 c-e)$. Staining for GFAP (gliogenic lineage) (Fig. 2a, d, e) showed similar findings [control $(n=4), 97.79 \pm 7.55$; sham $(n=$ 5), $160.2 \pm 2.705$; and GMH $(n=4), 265.9 \pm 48.25$; $p=$ 0.004 , ANOVA). Colocalisation analysis revealed a significant increase in the number of cells colocalising
MASH1 and EdU [control $(n=4), 9 \pm 2.97$, and GMH $(n=4), 29.5 \pm 4.66 ; p=0.01, t$ test $]$ and in the number of cells colocalising GFAP and EdU [control $(n=4)$, $32.13 \pm 5.23$; sham $(n=5), 47.63 \pm 3.5$; and GMH $(n=4)$, $101.2 \pm 19.69 ; p=0.004$, ANOVA]

To exclude that the increase in the number of EdU ${ }^{+v e}$ cells within the SVZ could be accounted for by an infiltration of inflammatory cells, we stained for the microglial

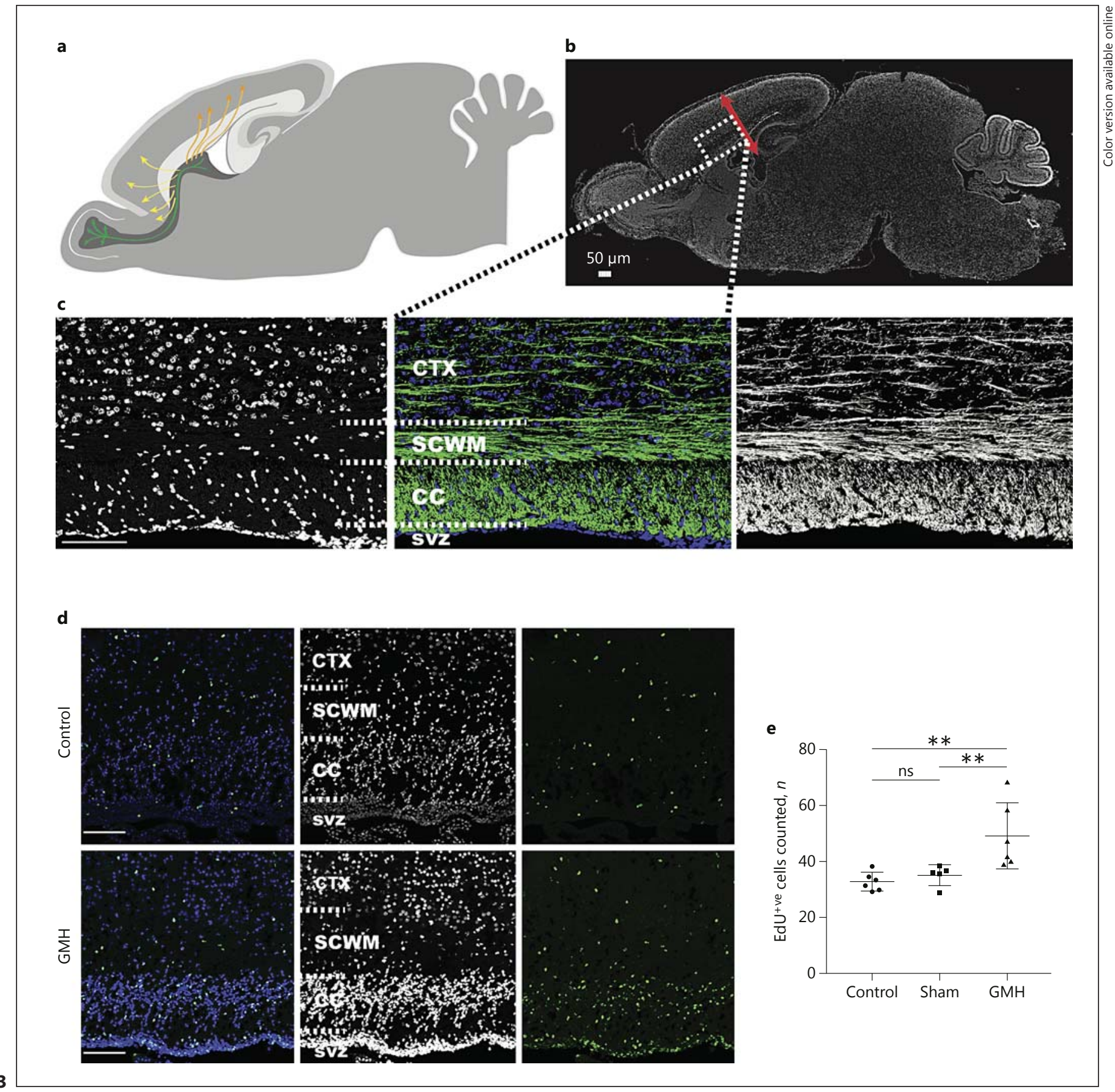

(For legend see next page.) 
marker Iba1. We show that whilst a significant inflammatory response was elicited by blood injection as evidenced by the significant increase in the number of Iba $1^{\text {+ve }}$ cells counted within the SVZ following GMH [ control $(n=4)$, $14 \pm 2.35$, and GMH $(n=4), 30.8 \pm 5.1 ; p=0.02, t$ test], this did not account for the significant rise in the number of EdU ${ }^{+v e}$ cells as the majority of the EdU ${ }^{+v e}$ cells were Iba1 negative (online suppl. Fig. S5).

In summary, we have shown that GMH causes an increase in the number of EdU ${ }^{\text {+ve }}$ cells within the wall of the lateral ventricle, with a significant increase in the number of transient amplifying cells and glial cells.

\section{GMH Causes an Increase in the Number of $N G 2^{+v e}$}

Progenitors within the Corpus Callosum

While carrying out the analysis within the lateral wall of the lateral ventricle as described above, it became apparent that increased numbers of EdU ${ }^{+v e}$ cells were also seen within the callosal/dorsal border of the ventricle, a finding which was also seen in MASH1 staining (Fig. 2c). This area was recognised by Suzuki and Goldman [34] as a key postnatal gliogenic migratory pathway out of the SVZ and into the cortex (Fig. 3a); thus, to quantify this increase, analysis was undertaken within the corpus callosum on an independent series of sagittally sectioned brains (Fig. 3b, c).

The first most striking finding was that the blood-injected samples exhibited a different morphology within the corpus callosum. The normal perpendicular arrangement of cells was replaced by a markedly hypercellular and disordered pattern (Fig. 3d). Quantification of the number of EdU ${ }^{+v e}$ cells again demonstrated a significant increase following IC blood injection, which was not found in the sham control [control $(n=6), 32.73 \pm 1.386$; sham $(n=5), 35.03 \pm 1.662$; and GMH $(n=6), 49.09 \pm 4.83 ; p=$

Fig. 3. Germinal matrix haemorrhage $(\mathrm{GMH})$ leads to an increase in the number of EdU ${ }^{+v e}$ transient amplifying cells within the corpus callosum. a Sagittal schematic representation of the P4 mouse brain demonstrating the postnatal migratory patterns out of the subventricular zone (SVZ) (adapted from Suzuki and Goldman [34]). Neuronal migration into the olfactory bulb is shown in green whilst glial migratory pathways are shown in yellow and orange. b Sagittal single-channel DAPI image from a P4 mouse pup demonstrating the positioning of the 300-pixel-wide counting frame (rectangle) orientated anterior to a line drawn perpendicular to the anterior border of the hippocampus (double-headed arrow). c Example of the counting frame used for quantification in the sagittal analysis. Left: single-channel DAPI image demonstrating 4 phenotypically different regions: the SVZ, the corpus callosum (CC), the subcortical white matter (SCWM), and the cortex (CTX). Quantification was undertaken within the CC. Middle: myelin basic pro-
0.0049, ANOVA] (Fig. 3e). Colocalisation revealed a significant increase in $\mathrm{NG}^{+\mathrm{ve}} \mathrm{EdU}^{+\mathrm{ve}}$ cells [control $(n=6)$, $11.67 \pm 2.362$, and GMH $(n=6), 20.17 \pm 1.558 ; p=0.013$, $t$ test), with a trend for increase also seen in the GFAP ${ }^{+v e /}$ $\mathrm{EdU}^{+\mathrm{ve}}$ population, whilst no increase was seen in the number of cells colocalising EdU and Dcx (Fig. 4).

The corpus callosum is thought to represent a major conduit of glial progenitors migrating from the SVZ to the cortex [34]. Here we showed that GMH not only impacts on the SVZ but also leads to an increase in the number of $\mathrm{NG}^{\text {+ve }}$ lineage-committed progenitors in the corpus callosum.

\section{Reduced Expression of Olig2 at P21 after GMH}

Given that we have shown that GMH causes phenotypic changes within the SVZ and the corpus callosum at an acute/immediate stage (P4), we resolved to determine how this might impact early cortical development. To achieve this, we analysed the neocortex from P21 mice as this was felt to be representative of juvenile brain development (Fig. 5a).

We found that GMH causes a significant reduction in the percentage of EdU ${ }^{+v e}$ cells [control $(n=3), 13.66 \pm$ 0.86 , and GMH $(n=3), 9.88 \pm 0.45 ; p=0.017, t$ test $]$ (Fig. 5b) throughout the cortex and it was not limited to any specific layer. Costaining with the panneuronal marker NeuN revealed that in the control setting less than $1 \%$ of the DAPI cells counted were found to be labelled for both EdU and NeuN and this was not found to be significantly affected by GMH (Fig. 5c).

Further costaining with the oligodendrocyte marker Olig2 revealed that while in the control setting around 9\% of the cells were labelled with EdU and Olig2 this was seen to drop significantly to around 6\% following GMH [con- tein (green) staining used to demonstrate the anatomical boundaries between the SCWM and the CC facilitating quantification within the CC. Right: single-channel myelin basic protein highlighting the different orientation of myelin staining seen in the SCWM, CC, and CTX . d Oil tile scans $(\times 40)$ (blue, DAPI, and green, EdU) following GMH shows that the cellular architecture within the CC is abnormal, with markedly increased cellularity and loss of the perpendicular arrangement of nuclei (as seen in the control samples). Similarly, we see a significant increase in the number of EdU ${ }^{+v e}$ cells within the SVZ and the CC whilst the SCWM and the CTX remain relatively unaffected. e Quantification of the number of EdU ${ }^{+v e}$ cells within the counting frame of the CC reveals that GMH causes a significant increase in the number of EdU ${ }^{+v e}$ cells (control, $n=6$; sham, $n=5$; and GMH, $n=6$; $p<0.01$, ANOVA). Scale bars, $100 \mu \mathrm{m}\left({ }^{*} \mathrm{p}<0.05 ;{ }^{* *} \mathrm{p}<0.01\right)$.
Neural Stem Cells and Neonatal Brain Haemorrhage
Dev Neurosci 2016;38:430-444

DOI: $10.1159 / 000455839$
437 


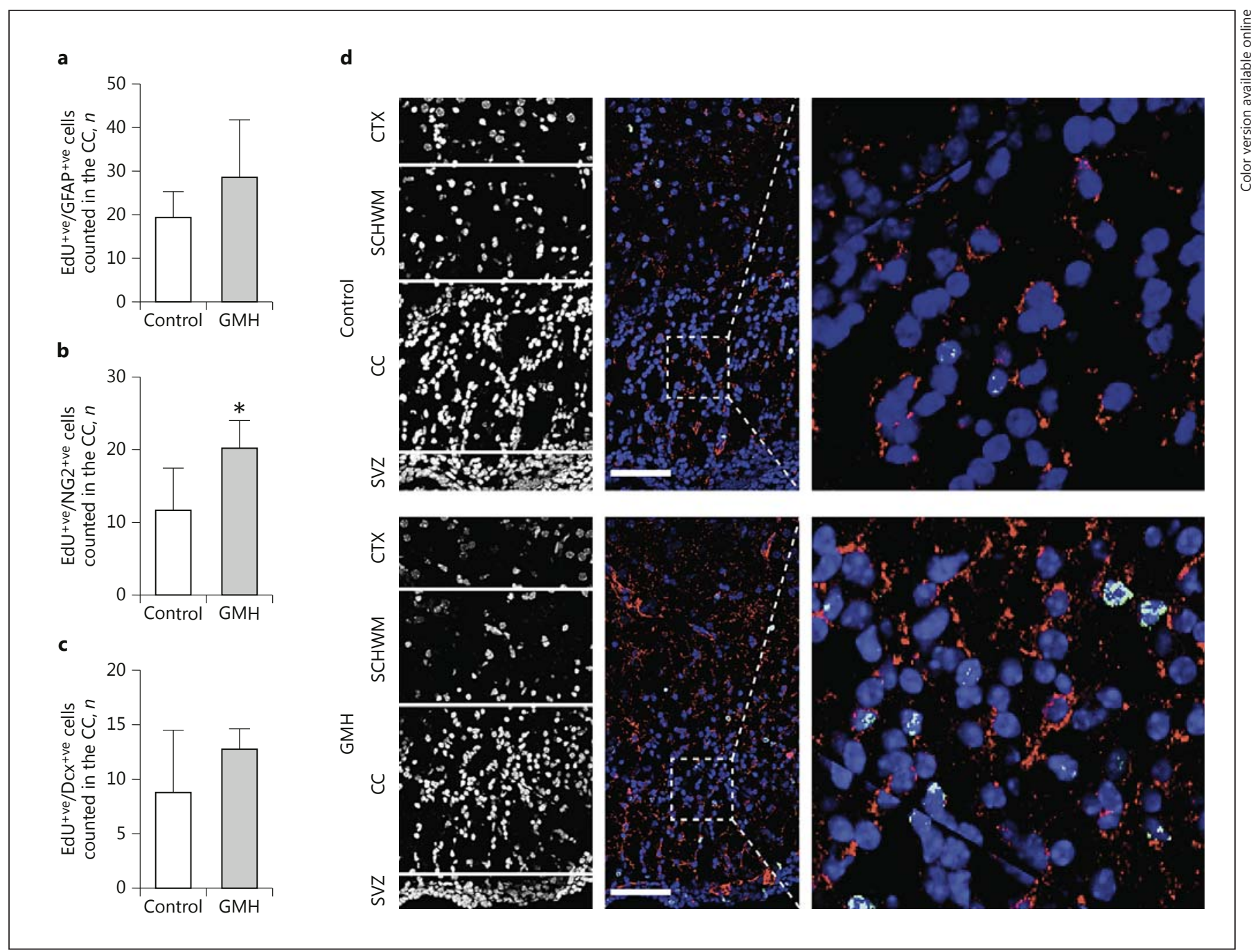

Fig. 4. Germinal matrix haemorrhage $(\mathrm{GMH})$ causes an increase in glial progenitors within the corpus callosum. Quantification of the number of cells which colocalise GFAP (a), NG2 (b), and Dcx (c) reveals that GMH causes a significant increase in the number of cells which colocalise EdU and NG2, with a similar trend seen in the number of cells colocalising EdU and GFAP, with no comparative increase seen in the number of cells colocalising EdU and Dcx. d Representative example showing that GMH causes an increase in the number of cells which colocalise EdU (green) and NG2 (red). Scale bars, $100 \mu \mathrm{m}\left({ }^{*} \mathrm{p}<0.05\right)$. trol $(n=3), 8.54 \pm 0.34$, and GMH $(n=3), 6.07 \pm 0.35 ; p=$ $0.007, t$ test) (Fig. $5 \mathrm{~d}$ ). Similarly, the percentage of cells expressing Olig2 was seen to significantly decrease following $\mathrm{GMH}[\operatorname{control}(n=3), 12.69 \pm 0.53$, and GMH $(n=3), 9.63$ $\pm 0.61 ; p=0.019$, $\mathrm{t}$ test $]$ (Fig. $5 \mathrm{e}$ ).

Taken together, these data suggest that GMH has a negative impact on postnatal oligodendrogenesis while not significantly affecting postnatal neurogenesis. Whether this is due to direct toxicity or to an impact on differentiation or migration of oligodendrocyte precursors remains to be definitively clarified.

\section{Moderate GMH Causes Transient Early Impacts on \\ Neonatal Development}

Following IC blood injection at P0, we observed an increased number of falls [control $(n=15), 4.5$; sham $(n=$ $12), 9.33$; and GMH $(n=21), 22.23$; ANOVA] and significantly more fails in grip strength testing [control $(n=15)$, 1.875; sham $(n=12), 1.83$; and GMH $(n=21), 2.47$; ANOVA] from P3 to P6; however, this difference did not persist and, contrary to published models of GMH (Aquilina et al. [24], Xue et al. [26], Lekic et al. [25]), we found no persistent deficits/alterations in neuromotor development up to 


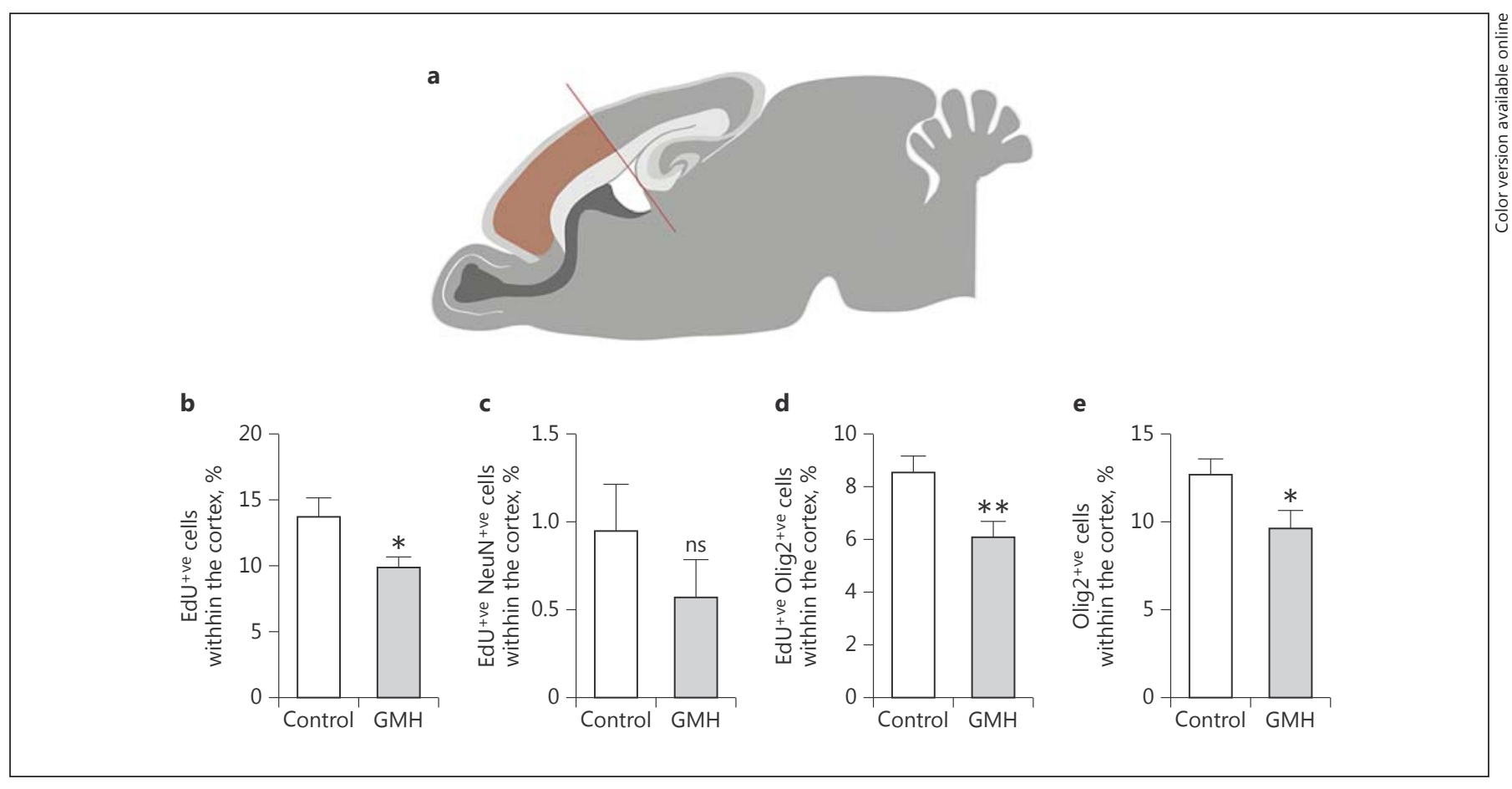

Fig. 5. Germinal matrix haemorrhage $(\mathrm{GMH})$ at $\mathrm{P} 0$ impacts early cortical development (quantified on P21). a Quantification was undertaken in the neocortex anterior to a line drawn perpendicular to anterior border of the hippocampus (area shaded in red). b GMH at P0 significantly reduces the percentage of cells which express EdU within the cortex at P21 (control, $n=3$, and GMH, $n$ $=3 ; p<0.05, t$ test). $\mathbf{c}$ No significant change is seen in the percentage of cells which colocalise EdU and NeuN (control, $n=3$, and

P21 (online suppl. Fig. S4). This finding differentiates our model as being more representative of low-grade GMH, i.e., Papile grades II and III in contrast with the grade IV haemorrhage modelled by previously published studies [24-26]. This finding further reinforces the need for this model of low-grade GMH and implies that the global impact of grade IV haemorrhage may mask the more subtle impact that GMH/IVH has on the NSPC within the SVZ.

\section{GMH Causes Notch Downregulation in CD133+ve}

Cells in the SVZ

Next, we set out to assess the impact of GMH on molecular regulation within the proximal/ventricular domain. To this end, MACS sorting of prominin/CD133labelled cells from a single hemisphere of P4 blood-injected versus control pups was carried out. Prominin is a transmembrane glycoprotein expressed by ependymal cells and on the primary cilia of NSPC [35] within the SVZ its expression decreases throughout the course of

Neural Stem Cells and Neonatal Brain Haemorrhage
$\mathrm{GMH}, n=3 ; p=0.1, t$ test). $\mathbf{d}$ In contrast, analysis of colocalisation with markers of oligodendrocytic lineage reveals that GMH significantly reduces the proportion of cells which colocalise EdU and Olig2 (control, $n=3$, and GMH, $n=3 ; p<0.01$, $t$ test). e Similarly, following $\mathrm{GMH}$ at $\mathrm{P} 0$ we see a significant reduction in the percentage of cells which express the oligodendrocyte marker Olig2 (control, $n=3$, and GMH, $n=3 ; p<0.05, t$ test $)\left({ }^{*} \mathrm{p}<0.05 ;{ }^{* *} \mathrm{p}<0.01\right)$.

gestation but it is highly conserved within the ventricular/ proximal domain at $\mathrm{P} 4$ [36].

Expression analysis of a selection of genes known to play a role in SVZ NSPC regulation was carried out on RNA extracted from the injured hemisphere of 3 animals and uninjured controls. Eight genes were found to be significantly deregulated, with only Hsp90ab1 being upregulated and all others, i.e., Notch2, Ep300, Kat2a, Sox2, Cxcl12, Tubb3, and Ccne1 downregulated (Fig. 6a).

Given the integral role that the Notch pathway has in modulating stem cell proliferation and differentiation, we were intrigued to find that Notch 2 expression was downregulated $>25$-fold following GMH. To validate these findings, in situ hybridisation for the Notch pathway effector Hes 5 was used (control, $n=3$, and GMH, $n=3$ ). In the uninjured P4 SVZ, Hes5 was expressed in both the ependymal lining and a few scattered $\mathrm{GFAP}^{+\mathrm{ve}}$ cells, as demonstrated by double staining for GFAP/Hes5 (Fig. 5b). A striking reduction of Hes5 staining was ob-

Dev Neurosci 2016;38:430-444 


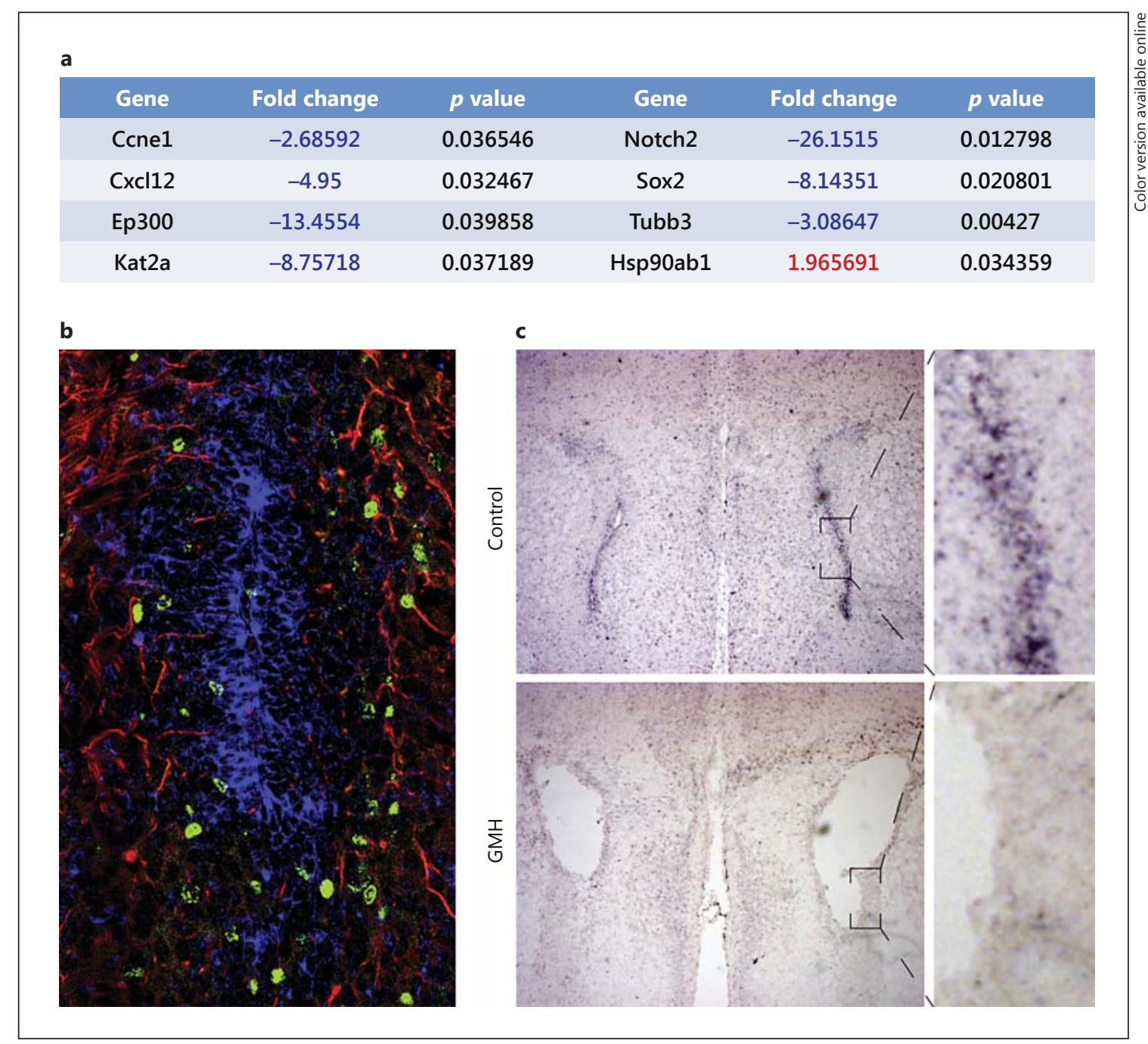

Fig. 6. Germinal matrix haemorrhage (GMH) causes downregulation of Notch2 in CD133-positive cells within the wall of the lateral ventricle. a RNA analysis from the $\mathrm{CD} 133^{\text {+ve }}$ cell fraction isolated from the wall of the lateral ventricle reveals that GMH causes significant downregulation of Ccne1, Cxcl12, Ep300, Kat2a, Notch2, Sox2, and Tubb3 and significant upregulation of Hsp90ab1 (control, $n=3$, and GMH, $n=3$; $p$ values shown were calculated using a $t$ test). b By overlaying the Hes5 ISH with the

served in the SVZ of P4 mice following GMH in all of the samples tested, and this was particularly marked in the anterior SVZ (Fig. 5c).

The observed downregulation of the Notch pathway in $\mathrm{CD} 133^{+\mathrm{ve}}$ cells in the SVZ after GMH raises the possibility that Notch signalling could be functionally mediating the proliferative burst of transient amplifying cells with subsequent aberrant differentiation observed in the mature cortex.
GFAP/EdU IHC, we confirm the expression of Notch within the wall of the lateral ventricle predominantly in $\mathrm{GFAP}^{-v e}$ cells with occasional expression in GFAP ${ }^{+v e}$ cells. c Photomicrographs showing in situ hybridisation performed using a Hes5 probe [32] on coronal sectioned P4 mouse brain. Specific localisation of the Hes 5 probe to the wall of the lateral ventricle in the control setting is clearly seen (top left and right) with a significant reduction in Hes5 expression following GMH (bottom left and right).

\section{Discussion}

Despite advances in perinatal care, encephalopathy of prematurity is still a common cause of disability in children and GMH is the most prevalent intracranial lesion seen in premature babies [37]. Due to the multifactorial nature of encephalopathy of prematurity [23], isolating the impact of GMH and deciphering its effect on the NSPC and cortical development remains elusive. 
The severity of haemorrhage correlates with outcomes [38] and ranges from minor bleeds within the substance of the GM to significant life-threatening haemorrhages, which extend into the ventricle causing florid hydrocephalus and associated venous infarction [39]. There is widespread agreement that the outcome following high-grade haemorrhage is poor [40], and this is likely due in part to the destructive impact on the parenchyma [23]. However, the outcome following moderate/low-grade haemorrhage is more variable, with contradictory reports in the literature [41-43]. More advanced neuroimaging techniques have revealed that, even if development appears outwardly normal, functional MRI imaging following premature birth shows markedly abnormal connectivity and synchronisation $[44,45]$ and volumetric analysis indicates a reduced brain size and cortical gyration [46-49]. Postnatally developed neuronal cells [4] with reduced dendritic arborisation [45] are also being increasingly recognised as important consequences of premature birth.

Given the clinical significance of GMH, numerous models in different animal species have been trialled [50]; however, to date all models have focused on the severe end of the spectrum with extensive cortical injury where diffuse haemorrhage and marked disturbances in behaviour are seen $[25,51,52]$. It is well recognised that NSPC within the SVZ are exquisitely sensitive to microenvironmental cues $[9,10]$ and further that haemorrhage within the ventricle alters the expression of NSC modulators, such as TGF $\beta$ [53]. Thus, in order to understand how GMH impacts NSPC and cortical development in the intermediate group, in whom outcomes appear to be most variable and who may have the most to gain from intervention, a more subtle injury model is needed. Currently available physiological techniques [52] cannot be used to model low-grade GMH as it causes widespread haemorrhage within the brain parenchyma [50] and may also be confounded by the use of glycerol, which has been shown to impact cortical development independently [54]. Similarly, the interpretation of results following the injection of collagenase into the SVZ [25], whilst reducing bolus size, is significantly limited due to the potentially confounding affect of collagenase on the NSPC.

Modelling intracerebral haemorrhage through targeted mutations within components of the blood-brain barrier has been instrumental in determining the aetiology of $\mathrm{GMH}$; for example, the roles of integrins [55], collagen [56], and pericytes [57] have all been shown. Furthermore, using a tetracycline-inducible system to initiate VEGF expression within the GM of the developing embryo, Yang

Neural Stem Cells and Neonatal Brain Haemorrhage et al. [58] showed high rates of IVH. The transgenic models developed to date invariably cause intrauterine bleeding and are associated with a high perinatal mortality. Thus, no widely accepted transgenic model of neonatal GMH has yet been developed to determine how postnatal haemorrhage impacts cortical development.

We chose to use injection of autologous blood to circumvent the potentially misleading influence of using nonphysiological substances. Similarly, reducing the volume of injection to $5 \mathrm{uL}$ and employing a stereotactic injection technique limits the kinetic impact of the blood bolus and focuses the lesion within the SVZ whilst limiting the collateral damage to the surrounding parenchyma. The fact that stereotactic blood injection causes minimal primary damage to the cortex with low rates of porencephalic cyst formation, whilst accurately modelling ventriculomegaly and microglial activation, reinforces the premise that the effect of GMH, in this model, is subtle and offers a unique opportunity to understand how moderate degrees of haemorrhage impact on the NSPC and cortical development.

Our primary finding of an increased number of EdU ${ }^{+v e}$ cells in the wall of the lateral ventricle at $\mathrm{P} 4$ following $\mathrm{GMH}$ at $\mathrm{P} 0$ was initially unexpected given that a previous blood injection model had shown a reduction in proliferation following GMH [26]. This likely reflects the different degrees of haemorrhage modelled by the two approaches. The finding of activation of proliferation following GMH is in keeping with ischaemic models of premature brain injury [59]; whilst differences may exist in the temporal course (delayed response seen following ischaemia and a more immediate response seen following haemorrhage), this finding suggests activation of a common pathway following brain injury in the premature neonate.

Costaining within the $\mathrm{SVZ}$ at $\mathrm{P} 4$ revealed that the increase in EdU ${ }^{\text {+ve }}$ cells seen following GMH was in part accounted for by an increase in the number of $\mathrm{MASH} 1^{+\mathrm{ve}}$ and $\mathrm{GFAP}^{+\mathrm{ve}}$ progenitor cells. In addition to this, analysis of the postnatal gliogenic migratory pathway out of the SVZ [34] (i.e., within the corpus callosum) revealed a significant increase in the number of glial progenitors $\left(\mathrm{EdU}^{+\mathrm{ve}} / \mathrm{NG}^{+\mathrm{ve}}\right)$ following GMH/IVH. This combination of findings implicates that moderate-grade GMH associated with intraventricular extension causes activation of proliferation within the SVZ, with a consequent increase in the number of glial progenitors within the postnatal migratory pathways.

Interestingly, by analysing the neocortex at P21 we found that this initial burst of proliferation of glial pro-

Dev Neurosci 2016;38:430-444

DOI: $10.1159 / 000455839$ 
genitors did not increase the proportion of glial cells within the cortex. Indeed, the opposite was seen, with reduced numbers of Olig2 ${ }^{\text {tve }}$ cells seen within the neocortex. This finding implies that the burst of glial progenitor cells produced by the activation of precocious proliferation within the SVZ (in reaction to GMH/IVH) is unable to integrate within the cortex and that the developing cortex is unable to compensate for the loss of potential and abnormal temporal activation.

These intriguing findings led us to speculate that $\mathrm{GMH}$ may have been impacting the molecular control of NSPC within the proximal/ventricular domain of the SVZ in our model. To address this question, we decided to isolate cells from the proximal/ventricular domain of the neonatal pup using a CD133 MACS protocol. Whilst no single marker has been demonstrated to show absolute sensitivity and specificity, CD133 is a robust and widely accepted marker of ependymal cells and NSC in the early postnatal brain [30].

Expression analysis demonstrated that moderategrade GMH downregulates Notch2 within the CD133 $3^{\text {+ve }}$ cell fraction (Fig. 6a). The periventricular location of Notch signalling downregulation following GMH was confirmed using in situ hybridisation directed against Hes5, a downstream effector of the Notch pathway (Fig. 6c).

The role of the Notch signalling pathway in the maintenance and differentiation of SVZ NSC is well characterised. Evidence of activation of the pathway in quiescent NSC was shown in transgenic mice in which the expression of a reporter gene was driven by the Hes 5 promoter or RBPj-binding sites, and its main role was found to be the maintenance of the pool of undifferentiated quiescent NSC [14]. In fact, conditional inactivation of the pathway led to a premature conversion of slowly dividing NSC into transient amplifying cells, a phenomenon accompanied by a proliferative burst which led to premature differentiation of the cells and to depletion of the pool of undifferentiated NSC as well as subsequent premature cessation of neurogenesis [14]. In our model of GMH, we found profound disruption of the SVZ including the ependymal lining and concomitant decrease in Notch activity as assessed based on a reduced number of cells expressing the Notch signalling downstream effector Hes5. It is conceivable that the decreased Notch signalling may be responsible for the proliferative burst of transient amplifying progenitors observed at $\mathrm{P} 4$. These data are in agreement with previous studies in which disruption of the ependymal cells by an ischaemic injury led to decreased Notch signalling, which in turn induced a fate change followed by cell cycle entry and neuronal differentiation [60]. We did not observe increased neuronal differentiation in our model at P21 but we did see decreased oligodendrogenesis instead, possibly because our injury strategy mainly affects the dorsal and anterior SVZ, an area where NSC with oligodendrocytic potential are enriched for [61]. These results are also in keeping with the reported role of Notch signalling in favouring oligodendrocytic specification [62].

Furthermore, Notch has an important role in dendritic arborisation of immature neurons in the adult brain. In fact, conditional knockout of Notch 1 results in significantly less complex arborisation, while overexpression of activated Notch 1 leads to a significant increase in dendritic complexity in newborn, maturing granule cells of the adult dentate gyrus [63]. Future studies will tell whether similar abnormalities are seen at later stages in our mouse model, since they could provide a preliminary explanation for subtler neurocognitive sequelae suffered by GMH patients later in their life.

It will be important to assess the translational value of these findings in human autoptic GMH brain tissue as Notch downregulation may represent a final common pathway following premature birth. Should this be the case, quantification of Notch expression in the GM may prove a useful prognostic indicator and, importantly, pharmacological activation of the Notch pathway, which has been shown to be achievable and to exert the predicted functional impact in human cells $[64,65]$, could be therapeutically pursued.

Taken together, these findings raise the possibility that activation of Notch signalling could be a therapeutic strategy for GMH and our mouse model would be an ideal platform to test this hypothesis at a preclinical level.

\section{Acknowledgements}

We thank all of the members of the Marino Lab for helpful discussions. We are grateful to the BSU staff for help in the daily care of our mouse colony. This work was supported in part by grants from the British Neuropathological Society, the Royal College of Surgeons, SPARKS - the Children's Medical Research Charity (11QMURTF13), and the Barts and London Charity (468/1739).
442

Dev Neurosci 2016;38:430-444 DOI: $10.1159 / 000455839$
Dawes/Zhang/Fancy/Rowitch/Marino 


\section{References}

1 Chang HH, Larson J, Blencowe H, Spong CY, Howson CP, Cairns-Smith S, Lackritz EM, Lee SK, Mason E, Serazin AC: Preventing preterm births: analysis of trends and potential reductions with interventions in 39 countries with very high human development index. Lancet 2013;381:223-234.

2 Goldenberg RL, Culhane JF, Iams JD, Romero R: Epidemiology and causes of preterm birth. Lancet 2008;371:75-84.

3 Ballabh P: Intraventricular hemorrhage in premature infants: mechanism of disease. Pediatr Res 2010;67:1-8.

4 Back SA: Brain injury in the preterm infant: new horizons for pathogenesis and prevention. Pediatr Neurol 2015;53:185-192.

5 Fleiss B, Gressens P: Tertiary mechanisms of brain damage: a new hope for treatment of cerebral palsy? Lancet Neurol 2012;11:556-566.

6 Hack M, Wilson-Costello D, Friedman $\mathrm{H}$, Taylor GH, Schluchter M, Fanaroff AA: Neurodevelopment and predictors of outcomes of children with birth weights of less than 1,000 g: 1992-1995. Arch Pediatr Adolesc Med 2000;154:725-731.

7 Vohr BR, Wright LL, Poole WK, McDonald SA: Neurodevelopmental outcomes of extremely low birth weight infants $<32$ weeks' gestation between 1993 and 1998. Pediatrics 2005; 116:635-643.

8 Wood N, Costeloe K, Gibson A, Hennessy E, Marlow N, Wilkinson A: The EPICure study: associations and antecedents of neurological and developmental disability at 30 months of age following extremely preterm birth. Arch Dis Child Fetal Neonatal Ed 2005;90:F134F140.

9 Tong CK, Alvarez-Buylla A: SnapShot: adult neurogenesis in the V-SVZ. Neuron 2014;81: 220-220 e221.

10 Fuentealba LC, Obernier K, Alvarez-Buylla A: Adult neural stem cells bridge their niche. Cell Stem Cell 2012;10:698-708.

11 Lehtinen MK, Zappaterra MW, Chen X, Yang YJ, Hill AD, Lun M, Maynard T, Gonzalez D, Kim S, Ye P, D'Ercole AJ, Wong ET, LaMantia AS, Walsh CA: The cerebrospinal fluid provides a proliferative niche for neural progenitor cells. Neuron 2011;69:893-905.

12 Lim DA, Tramontin AD, Trevejo JM, Herrera DG, García-Verdugo JM, Alvarez-Buylla A: Noggin antagonizes BMP signaling to create a niche for adult neurogenesis. Neuron 2000; 28:713-726.

13 Kopan R, Ilagan MXG: The canonical Notch signaling pathway: unfolding the activation mechanism. Cell 2009;137:216-233.

14 Imayoshi I, Sakamoto M, Yamaguchi M, Mori K, Kageyama R: Essential roles of Notch signaling in maintenance of neural stem cells in developing and adult brains. J Neurosci 2010; 30:3489-3498.
15 Liu X, Wang Q, Haydar TF, Bordey A: Nonsynaptic GABA signaling in postnatal subventricular zone controls proliferation of GFAP-expressing progenitors. Nat Neurosci 2005;8:1179-1187.

16 Shen Q, Goderie SK, Jin L, Karanth N, Sun Y, Abramova N, Vincent P, Pumiglia K, Temple S: Endothelial cells stimulate self-renewal and expand neurogenesis of neural stem cells. Science 2004;304:1338-1340.

17 Sanai N, Nguyen T, Ihrie RA, Mirzadeh Z, Tsai HH, Wong M, Gupta N, Berger MS, Huang E, Garcia-Verdugo JM, Rowitch DH, Alvarez-Buylla A: Corridors of migrating neurons in the human brain and their decline during infancy. Nature 2011;478:382-386.

18 Paredes MF, James D, Gil-Perotin S, Kim H, Cotter JA, Ng C, Sandoval K, Rowitch DH, Xu D, McQuillen PS: Extensive migration of young neurons into the infant human frontal lobe. Science 2016;354:aaf7073.

19 Ernst A, Alkass K, Bernard S, Salehpour M, Perl S, Tisdale J, Possnert G, Druid H, Frisén $\mathrm{J}$ : Neurogenesis in the striatum of the adult human brain. Cell 2014;156:1072-1083.

20 Kriegstein A, Alvarez-Buylla A: The glial nature of embryonic and adult neural stem cells. Annu Rev Neurosci 2009;32:149-184.

21 Menn B, Garcia-Verdugo JM, Yaschine C, Gonzalez-Perez O, Rowitch D, Alvarez-Buylla A: Origin of oligodendrocytes in the subventricular zone of the adult brain. J Neurosci 2006;26:7907-7918.

22 Back SA, Luo NL, Borenstein NS, Levine JM, Volpe JJ, Kinney HC: Late oligodendrocyte progenitors coincide with the developmental window of vulnerability for human perinatal white matter injury. J Neurosci 2001;21: 1302-1312.

23 Volpe JJ: Brain injury in premature infants: a complex amalgam of destructive and developmental disturbances. Lancet Neurol 2009; 8:110-124.

24 Aquilina K, Chakkarapani E, Love S, Thoresen $\mathrm{M}$ : Neonatal rat model of intraventricular haemorrhage and post-haemorrhagic ventricular dilatation with long-term survival into adulthood. Neuropathol Appl Neurobiol 2011;37:156-165.

25 Lekic T, Manaenko A, Rolland W, Krafft PR, Peters R, Hartman RE, Altay O, Tang J, Zhang $\mathrm{JH}$ : Rodent neonatal germinal matrix hemorrhage mimics the human brain injury, neurological consequences, and post-hemorrhagic hydrocephalus. Exp Neurol 2012;236:69-78.

26 Xue M, Balasubramaniam J, Buist RJ, Peeling J, Del Bigio MR: Periventricular/intraventricular hemorrhage in neonatal mouse cerebrum. J Neuropathol Exp Neurol 2003;62: 1154-1165.

27 Alles YC, Greggio S, Alles RM, Azevedo PN, Xavier LL, DaCosta JC: A novel preclinical rodent model of collagenase-induced germinal matrix/intraventricular hemorrhage. Brain Res 2010;1356:130-138.
28 Merkle FT, Mirzadeh Z, Alvarez-Buylla A: Mosaic organization of neural stem cells in the adult brain. Science 2007;317:381-384.

29 Inta D, Alfonso J, von Engelhardt J, Kreuzberg MM, Meyer AH, van Hooft JA, Monyer $\mathrm{H}$ : Neurogenesis and widespread forebrain migration of distinct GABAergic neurons from the postnatal subventricular zone. Proc Natl Acad Sci USA 2008;105:20994-20999.

30 Pfenninger CV, Roschupkina T, Hertwig F, Kottwitz D, Englund E, Bengzon J, Jacobsen SE, Nuber UA: CD133 is not present on neurogenic astrocytes in the adult subventricular zone, but on embryonic neural stem cells, ependymal cells, and glioblastoma cells. Cancer Res 2007;67:5727-5736.

31 Bolos V, Grego-Bessa J, de la Pompa JL: Notch signaling in development and cancer. Endocr Rev 2007;28:339-363.

32 Muzio L, Soria J, Pannese M, Piccolo S, Mallamaci A: A mutually stimulating loop involving emx2 and canonical wnt signalling specifically promotes expansion of occipital cortex and hippocampus. Cereb Cortex 2005; 15 : 2021-2028.

33 Fancy SP, Harrington EP, Yuen TJ, Silbereis JC, Zhao C, Baranzini SE, Bruce CC, Otero JJ, Huang EJ, Nusse R: Axin2 as regulatory and therapeutic target in newborn brain injury and remyelination. Nat Neurosci 2011;14: 1009-1016.

34 Suzuki SO, Goldman JE: Multiple cell populations in the early postnatal subventricular zone take distinct migratory pathways: a dynamic study of glial and neuronal progenitor migration. J Neurosci 2003;23:4240-4250.

35 Codega P, Silva-Vargas V, Paul A, Maldonado-Soto AR, DeLeo AM, Pastrana E, Doetsch F: Prospective identification and purification of quiescent adult neural stem cells from their in vivo niche. Neuron 2014;82:545-559.

36 Olausson KH, Maire CL, Haidar S, Ling J, Learner E, Nistér M, Ligon KL: Prominin-1 (CD133) defines both stem and non-stem cell populations in CNS development and gliomas. PLoS One 2014;9:e106694.

37 Brouwer A, Groenendaal F, van Haastert IL, Rademaker K, Hanlo P, de Vries L: Neurodevelopmental outcome of preterm infants with severe intraventricular hemorrhage and therapy for post-hemorrhagic ventricular dilatation. J Pediatr 2008;152:648-654.

38 Bassan H, Limperopoulos C, Visconti K, Mayer DL, Feldman HA, Avery L, Benson CB, Stewart J, Ringer SA, Soul JS, Volpe JJ, du Plessis AJ: Neurodevelopmental outcome in survivors of periventricular hemorrhagic infarction. Pediatrics 2007;120:785-792.

39 Papile L-A, Burstein J, Burstein R, Koffler H: Incidence and evolution of subependymal and intraventricular hemorrhage: a study of infants with birth weights less than 1,500 gm. J Pediatr 1978;92:529-534.
Neural Stem Cells and Neonatal Brain Haemorrhage
Dev Neurosci 2016;38:430-444

DOI: $10.1159 / 000455839$ 
40 Whitelaw A: Periventricular hemorrhage: a problem still today. Early Hum Dev 2012;88: 965-969.

41 Patra K, Wilson-Costello D, Taylor HG, Mercuri-Minich N, Hack M: Grades I-II intraventricular hemorrhage in extremely low birth weight infants: effects on neurodevelopment. J Pediatr 2006;149:169-173.

42 O'shea TM, Allred EN, Kuban KCK, Hirtz D, Specter B, Durfee S, Paneth N, Leviton A, Investigators ES: Intraventricular hemorrhage and developmental outcomes at 24 months of age in extremely preterm infants. J Child Neurol 2012;27:22-29.

43 Inder TE: Neurodevelopmental impact of low-grade intraventricular hemorrhage in very preterm infants. J Pediatr 2006; 149:152154.

44 Molnár Z, Rutherford M: Brain maturation after preterm birth. Sci Transl Med 2013;5: 168 ps162.

45 Dean JM, McClendon E, Hansen K, AzimiZonooz A, Chen K, Riddle A, Gong X, Sharifnia E, Hagen M, Ahmad T: Prenatal cerebral ischemia disrupts MRI-defined cortical microstructure through disturbances in neuronal arborization. Sci Transl Med 2013;5: 168ra167-168ra167.

46 Dubois J, Benders M, Cachia A, Lazeyras F, Leuchter RH-V, Sizonenko S, Borradori-Tolsa C, Mangin J, Hüppi PS: Mapping the early cortical folding process in the preterm newborn brain. Cereb Cortex 2008;18:1444-1454.

47 Toft PB, Leth H, Ring PB, Peitersen B, Lou HC, Henriksen O: Volumetric analysis of the normal infant brain and in intrauterine growth retardation. Early Hum Dev 1995;43: $15-29$.

48 Tolsa CB, Zimine S, Warfield SK, Freschi M, Rossignol AS, Lazeyras F, Hanquinet S, Pfizenmaier M, Hüppi PS: Early alteration of structural and functional brain development in premature infants born with intrauterine growth restriction. Pediatr Res 2004;56:132138.
49 Jary S, De Carli A, Ramenghi LA, Whitelaw A: Impaired brain growth and neurodevelopment in preterm infants with posthaemorrhagic ventricular dilatation. Acta Paediatr 2012;101:743-748.

50 Balasubramaniam J, Del Bigio MR: Animal models of germinal matrix hemorrhage. J Child Neurol 2006;21:365-371.

51 Balasubramaniam J, Xue M, Buist RJ, Ivanco TL, Natuik S, Del Bigio MR: Persistent motor deficit following infusion of autologous blood into the periventricular region of neonatal rats. Exp Neurol 2006;197:122-132.

52 Chua CO, Chahboune H, Braun A, Dummula K, Chua CE, Yu J, Ungvari Z, Sherbany AA, Hyder F, Ballabh P: Consequences of intraventricular hemorrhage in a rabbit pup model. Stroke 2009;40:3369-3377.

53 Whitelaw A, Christie S, Pople I: Transforming growth factor-beta1: a possible signal molecule for posthemorrhagic hydrocephalus? Pediatr Res 1999;46:576-580.

54 Traudt CM, McPherson RJ, Studholme C, Millen KJ, Juul SE: Systemic glycerol decreases neonatal rabbit brain and cerebellar growth independent of intraventricular hemorrhage. Pediatr Res 2014;75:389-394.

55 McCarty JH, Monahan-Earley RA, Brown LF, Keller M, Gerhardt H, Rubin K, Shani M, Dvorak HF, Wolburg H, Bader BL: Defective associations between blood vessels and brain parenchyma lead to cerebral hemorrhage in mice lacking av integrins. Mol Cell Biol 2002; 22:7667-7677.

56 Gould DB, Phalan FC, Breedveld GJ, van Mil SE, Smith RS, Schimenti JC, Aguglia U, van der Knaap MS, Heutink P, John SW: Mutations in Col4al cause perinatal cerebral hemorrhage and porencephaly. Science 2005;308: 1167-1171.

57 Lindahl P, Johansson BR, Levéen P, Betsholtz $\mathrm{C}$ : Pericyte loss and microaneurysm formation in PDGF-B-deficient mice. Science 1997; 277:242-245.

58 Yang D, Baumann JM, Sun Y-Y, Tang M, Dunn RS, Akeson AL, Kernie SG, Kallapur S, Lindquist DM, Huang EJ: Overexpression of vascular endothelial growth factor in the germinal matrix induces neurovascular proteases and intraventricular hemorrhage. Sci Transl Med 2013;5:193ra190-193ra190.
59 Fagel DM, Ganat Y, Silbereis J, Ebbitt T, Stewart W, Zhang H, Ment LR, Vaccarino FM: Cortical neurogenesis enhanced by chronic perinatal hypoxia. Exp Neurol 2006;199:7791.

60 Carlen M, Meletis K, Goritz C, Darsalia V, Evergren E, Tanigaki K, Amendola M, BarnabeHeider F, Yeung MS, Naldini L, Honjo T, Kokaia Z, Shupliakov O, Cassidy RM, Lindvall O, Frisen J: Forebrain ependymal cells are Notch-dependent and generate neuroblasts and astrocytes after stroke. Nat Neurosci 2009;12:259-267.

61 Ortega F, Gascón S, Masserdotti G, Deshpande A, Simon C, Fischer J, Dimou L, Lie DC, Schroeder T, Berninger B: Oligodendrogliogenic and neurogenic adult subependymal zone neural stem cells constitute distinct lineages and exhibit differential responsiveness to Wnt signalling. Nat Cell Biol 2013;15: 602-613.

62 Zhou Q, Choi G, Anderson DJ: The bHLH transcription factor Olig2 promotes oligodendrocyte differentiation in collaboration with Nkx2. 2. Neuron 2001;31:791-807.

63 Breunig JJ, Silbereis J, Vaccarino FM, Sestan N, Rakic P: Notch regulates cell fate and dendrite morphology of newborn neurons in the postnatal dentate gyrus. Proc Natl Acad Sci USA 2007;104:20558-20563.

64 Lobry C, Ntziachristos P, Ndiaye-Lobry D, Oh P, Cimmino L, Zhu N, Araldi E, Hu W, Freund J, Abdel-Wahab O: Notch pathway activation targets AML-initiating cell homeostasis and differentiation. J Exp Med 2013; 210:301-319.

65 Kannan S, Sutphin RM, Hall MG, Golfman LS, Fang W, Nolo RM, Akers LJ, Hammitt RA, McMurray JS, Kornblau SM: Notch activation inhibits AML growth and survival: a potential therapeutic approach. J Exp Med 2013;210:321-337. 